pyæmia, one was not benefited, and one very much, so as to be able to leave the hospital, though death ensued not long after. Here the pyæmia was complicated with soirrhus. The numbers are far too small to justify any positive conclusion, but the results afford some encouragement to the repetition of similar trials.

It may be well that I should tell you what I mean by the term " hyper-ventilation," which is perhaps convenient, though etymologically incorrect. To carry out the method completely, the first thing is to have a pure surrounding atmosphere, which of course involves that the hospital or the patient's residence be in a bealthy situation, say a breezy heath, or an upland, such as that on which the Caterham Lunatic Asylum stands. If such a site is unattainable, the next best thing is to have a lofty building, standing high above all sources of air-contamination, such as manure-heaps and gully-holes. The ward where all my patients (except one) were placed, stands about sixty feet above the ground, and as the windows were always opened from the top, the entering air came from a level outside about ten feet higher. It seemed fairly fresh and pure. If the patients are well supplied with good bed coverings, have warm shawls fastened round their shoulders, and hoods with flaps over their necks, they run no risk of being chilled by currents of cold air. The upper sash of the windows should be sufficiently lowered to leave a space of three or four feet vertical and of the width of an ordinary window, for the outside air to enter. The door should be open sufficiently to allow a very free passage of air, especially in the summer. In the winter a good fire should be kept up, and the door need not be so wide open. It is perhaps better that the patients' beds sbould not be placed directly between the windows and the door, but a little to one side. The nurses are to be strictly charged to keep the windows and doors open night and day-an injunction which, for their own comfort, they are too apt to disobey. Visits should therefore be made at unexpected hours.

Such ventilation as this is intended to place the patient in as nearly as possible the sime condition as if he were in the open air, except that he is sheltered from wet and cold, or excessive solar beat. Its object is to increase the aera. tion of the blood, induce or promote destructive oxidisation of morbid matters, and to favour also their elimination from the lungs in the expired air. It is a special means for special cases, and not at all to be regarded as a slight advance on the ordinary hygienic requirement. To many maladies it would be quite inappropriate or bighly per. nicious. I should never recommend it to sufferers from rheumatic fever, Bright's disease, laryngitis, acute or chronic bronchitis, or, indeed, to most of those labouring under our ordinary disenses. While believing strongly in the virtue of abundance of pure air, I equally believe in the injurious action of cold, which the Registrar.General has so forcibly demonstrated. I hold that for the proper management of our hospital cases it is of the first importance that they should be classified. Some there are to whom a warm genial atmosphere is quite necessary, others who need pure air in abundance no matter how cold, and others again who do well enough with moderate ventilation and moderate warmth. It is especially for cases of tuberculosis, pyæmia, septicæmia, puerperal fever, and perhaps typhus, that I advocate the trial of hyper-ventilation. Our means of help in these terrible disorders are all too scanty to warrant our neglecting any that seem rational or hopeful. The diffculties in the way of employing hyper-ventilation are of ten considerable, perhaps as much from the prejudices of the patient's friends as from any other cause. They are not, however, greater than those which the iced bath had to contend with, and will be easily overcome if we find that the remedy merits to be used.

Before concluding, I will make a few remarks on the great and often rapid variations of temperature which occurred in two of the cases of pyæmia, as they seem to have a considerable bearing on the theory of fever. Thus, as the table shows, in Case 2, at 10 P.M. on Oct. 10th the temperature was $100^{\circ}$; fourteen hours later it was $105^{\circ}$. On Nov. 5 th, about 10 P.M. it was $99 \cdot 8^{\circ}$; on the following day at noon it was $105.4^{\circ}$, and the same twenty-six hours later, but in twenty hours more it had fallen to $986^{\circ}$. On Nov. 13th the temperature was $105.2^{\circ}$ about $10 \mathrm{~A} . \mathrm{M}$.; at about $10 \mathrm{P.M}$. it was 99. In Case 6 the temperature at 10 A.M. on Dec. 10 th was $98^{\circ}$; at 11 A.M., during a rigor, it was $105^{\circ}$.
On the 15th, at 2 P.M., in a rigor, the temperature ware $106 \cdot 4^{\circ}$; about eight hours later it had fallen to $100 \cdot 8^{\circ}$. On the 17 th, at $11 \mathrm{~A}$ M., the temperature was $99.4^{\circ}$; at $6.30 \mathrm{P}$. 3 . it was $104.8^{\circ}$. On $\operatorname{Jan}$. 2nd, at 10 P.M., it was $105 \cdot 8^{\circ}$; twelve hours later it was $98 \cdot 4^{\circ}$. It is perfectly certain that the toxic matter, which was the primary cause of the disease in these instances, was present in the system, and effective during the whole time of their continuance. The protoplas of the body must have been similarly modified by it all the while. But the amount of heat generated by the infected protoplasm was very much influenced by some other factoz -viz., the "Etwas schutzendes," which, as Dr. B. Sanderson says, is of course the nervous system. Paralysis of heat regulating centres caused increased generation of beat.

\section{FILARIA SANGUINIS HOMINIS (MATURE FORM), FOUND IN A BLOOD_CLOT IN NAVOID ELEPHANTIASIS OF \\ THE SCROTUM.}

\section{Bx TIMOTHY LEWIS, M.B.,}

ARMT MRDTCAL DEPARTMENT, SPECIAL ASSIBTANT TO THR SANITART COMOISSIONER WITH THE GOVRRNMENT OF INDIA.

ThE LANCET of July 14th last contains a very interesting communication from Dr. Cobbold, announcing the discosery in Australia, by Dr. Bancroft, of "the sexually mature form of one, at least, of the various kinds of minute nematoid bæmatozoa." One of the specimens was obtained from a lymphatic abscess of the arm, and the others were caught in a trocar whilst puncturing a hydrocele of the spermatic cord. It will be interesting to know whether the blood of these persons contained embryoes of the same character as those referred to as escaping from the bodies of the trorms, and comparable to the filarix described by Carter, as hitherto none of the filariæ described by this disting uished observer have been found in the blood.

During the last five years $I$ have availed myself of every opportunity that presented itself of minutely examining the tissues of persons, who have either died or been operated upon, in whose blood the embryo fllaria sanguinis hominis: had been observed. All attempts, however, to find the parent worm had been unsuccessful. Speaking of these matters a short time ago with Dr. Gayer, professor of surgery at the Medical College, Calcutta, he very hindly promised to let me have for examination the diseased growth of the first case of "nævoid elephantiasis" of the scrotum which might be operated upon by him.

Yesterday (August 7th) such an opportunity occurred. A. young Bengalee was admitted into hospital, under Dr。 Gayer's care, affected with disease of the scrotum of this nature. It was a very characteristic example of the a fiection; the cutaneous tissues manifested the usual soft spongy character, witb, here and there, somewhat bleb-like elevations, but unaccompanied by any sero-chylous discharge, nor was there a history of previous chyluria. ${ }^{1}$ The first incision, however, revealed the fact that the tissues wcre soaked in chylo-serous fluid of a pinkish hue, which rapidly coagulated. This exudation flowed copiously from the incised tissue, although the general eirculation was completely arrested by means of an elastic bandage. The fuide which thus escaped, the diseased tissues, the fluid from a hydocele of the cord, and some varicose enlargements around the tissues surrounding the cord, were carefully collected in separate vessels, and removed for examination. The blood and the chylo-serous exudation from the diseased parte contained numerous embryo filariæ, but none could be foumd

1 I have, on former occasions, taken the opportanity of observing that this condition of the urine sometimes precedes, at other times follows, the manifestation of the scrotal affection; and that the fact of the vrine being. affected is sometimes concealed or disowned by the patient. There is a present, in the Medical College Hospital, a case recovering after an opera. tion for the removal of this elephantoid kind of scrotum, in whom $n$ suspicion of the co-existence of ehyluria was entertained antil after a atheter had been passed, and the state of the urine thus accidentoly detected. 
in the three or four ounces of the straw-coloured fluid of the hydrocele, nor were there any attached to the inner surface of the sac, the whole of which was carefully explored, and the epithelial lining soraped with the edge of a cover-glass,

This was the fourth pathological specimen of this character in which I had searched for the mature entozoon, the embryoes being present in abundance; and yesterday, after spending some eight hours in going through the removed tissues one after another, it seemed as if this search also would prove negative. At last, however, whilst teasing a blood-clot under a dissecting microscope, my eye was arrested by white thread-like objects in a state of great activity. These, on being transferred for examination under a higher power, were found to be specimens of two mature filarix. One of these contained ova, with embryoes identical in appearance with the free embryoes in the blood, in the exudation, and in the tissues. The other specimen was thinner, and had been so far injured by the needles used in teasing the clot as to have lost both terminal ends. What remained was about half an inch in length; it was of firmer consistence, and manifested a stronger tendency to maintain a coiled condition. It measured transversely $\frac{1}{18} 0^{\prime \prime}$, and the contained alimentary tube $\frac{1}{6}{ }^{\prime}=$. Another tube was in. cluded in the cavity of the specimen, suggestive of its being a male, as, from its microscopic characters, it closely resembled the spermatic duct of some other nematoid blood-worms which have come under my observation. The female worm also had suffered from the needles, for the caudal end had been eevered and could not be found, hence the total length of the parasite cannot be stated; the length of the portion secured was about $1 \frac{1}{2}$. It would occupy too much of the space of a journal devoted to medical subjects generally were an attempt made to give all the minute details of the microscopical character of the parasite; on the present occasion, therefore, I purpose restricting myself to giving a general description, with figures of such of the leading characters of the entozoon and of its contained progeny as will suffice to establish that it is the parent Filaria sanguinis hominis, together with such measurements as will enable comparisons to be made between it and such other mature nematoid hæmatozoa as have already been, or may still be, discovered in man and animals.

As already intimated, the parasite is of a white colour; the cuticle is smooth, and devoid of transverse markings, except such as are induced by the contraction of the subjacent muscular walls. The transverse measurement of the female worm where it is filled with ova $=\frac{1}{10}$ ". The woodcut (Fig. 1) represents the anterior portion of the mature entozoon, magnified 100 diameters. The head is seen to be slightly club-shaped; it measures $\frac{1}{10}$ across. The mouth does not manifest any distinctly marked labial subdivisions, nor are there any chitinous processes evident either before or after death. The diameter of the oral aperture $=\frac{1}{300} "$. The cesophagus does not manifest any very pronounced muscular striæ (they are more delicate than can be well indicated in a woodcut); it is $\frac{1}{55}$ " in length, and shades off almost imperceptibly into the intestinal tube; the latter measures across $\frac{1}{1} "$, and is filled with molecular and granular matter. 'The width of the parasite immediately below the cephalic extremity is $\frac{1}{545^{\prime \prime}}$, increasing to $\frac{1}{2^{2}} \frac{\text { at }}{2}$ the site where the cesophagus joins the intestine, and at a distance of another half-inch or so lower down acquiring the width of 1 " , or a little over.

The second figure represents the appearance of a portion of the worm where the uterine tubules are seen through its walls to be filled with ova in various stages of development. The intestinal tube may be seen winding along the side of the tubules. The latter are of very delicate texture, each measuring $\frac{1}{22} "$ across. These are filled with ova, and when firat examined the contents of many of the latter manifested distinct movements, the degree of activity corresponding to the extent of the maturity of the contained embryo. Ova in various stages of development could be observed packed together in the same part of the tubules.

The ova do not possess any distinctly marked "shell"; from the smallest to the largest nothing but a delicate pellicle can be distinguished as enveloping the embryo in all its stages; consequently the form assumed by the ovum depends to a great extent on tho degree of the surrounding pressure. To the right of the sketch (Fig. 3) will be seen figures of ova of various shape-spherical, triangular, oval, \&c., and with a considerable latitude as to size. The average of five measurements, taken at random, of the lessadvanced kind of ova-i.e., those in which the outline of the contained embryo was not distinctly evident $=\frac{1}{300}$ " by $\frac{1}{20} \sigma^{\prime \prime}$; whilst the average of three measurements of ova in which such embryoes were visible $=\frac{1}{60} "$ "by $\frac{1}{1790 "}$ ".

Fia. 2.
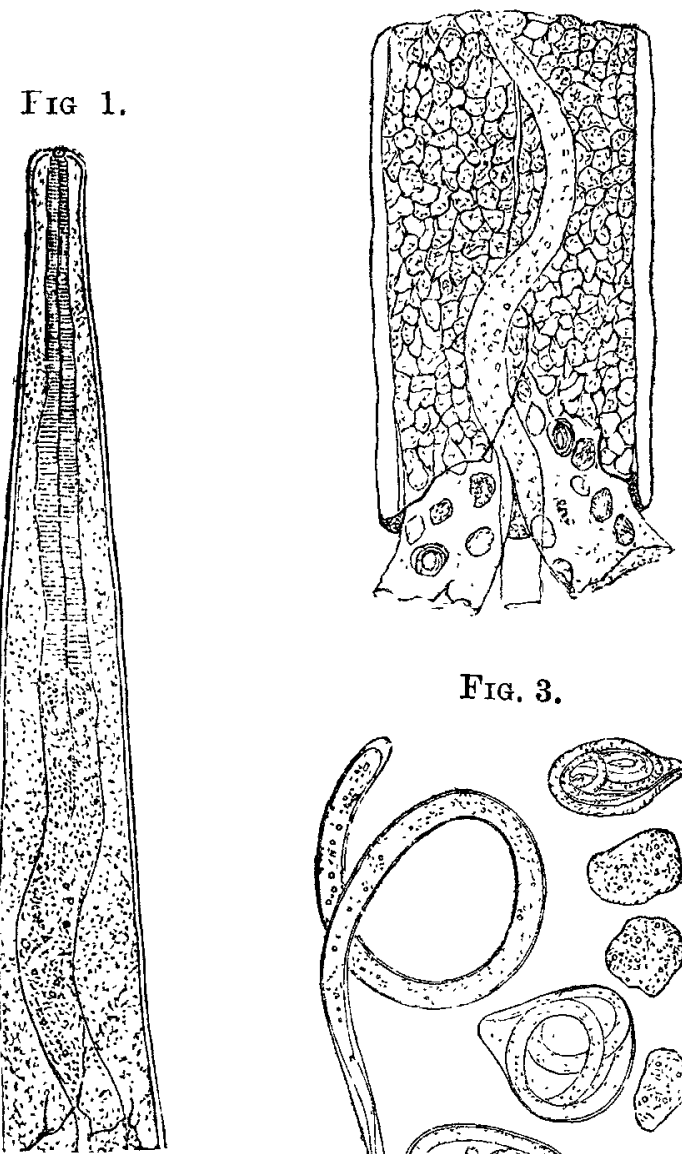

FIG. 3.

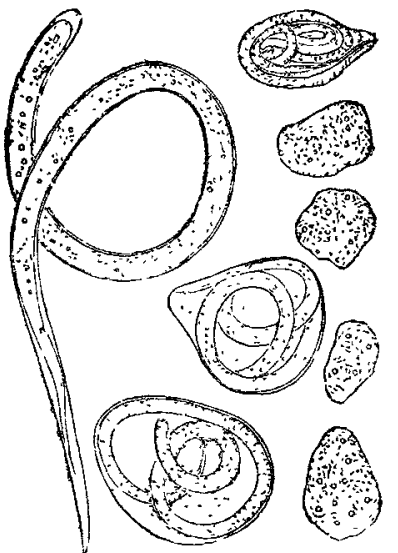

Fia. 1. - Anterior extremity of the mature Filaria sanguinis hominis. (Magnified 100 diameters.)

FIG. 2. - A portion of the mature Filaria sanguinis hominis showing uterine tubules flled with ova in various stages of derelopment diameters.)

FIG. 3. - Ova and embryoes of the Filaria sanguinis hominis. (Magnified 300 diameters.)

When the latter, after having arrived at this stage of development, are examined during life, it is in many in. stances difficult to state whether they are to be considered as freed embryoes or not, as the egg."shell" has become so extremely attenuated and translucent as only with difficulty to be distinguished. By pressing the covering-glass firmly, the sac may often be ruptured. It would, however, appear probable that, even when the embryo acquires worm.like appearances, the envelope is usually not lost in this species so long as it continues in the blood. On former occasions I have ventured to urge the importance of carefully noting whether, after a satisfactory examination of the living embryo-hæmatozoon, an enveloping sac could be distinguished or not, as it seemed to me, judging from the appearance observed in several hundred specimens of allied organisms in the blood of dogs in India, that this point would be of great value for diagnostic purposes. No sac has been observed surrounding such embryoes in the blood of dogs, nor in those found in man in Egypt.

In the same woodcut will be seen a representation of the embryo with its shell stretched to the full length of the worm, the specimen being in no way distinguishable from the embryoes found in the tissues and fluids above referred to, except in being smaller than the majority of them. These facts very strongly corroborate the view maintained by Leuckart with regard to embryo-hæmatozoa generally, that they do not advance in development so long as they 
remain in the blood. I have not seen a distinctly differentiated intestinal canal even in any of them, much less any indication of reproductive organs.

I have retained for the mature parasite the name originally applied to the embryo-applied obviously on the supposition that sooner or later the parent would be forthcoming. As it has, moreover, already been adopted by Leuckart in his recently completed standard work "On Parasites," and by other continental authorities, a new name, if not necessary on anatomical grounds, would only lead to confusion.

It is possible that when the parasite discovered by Dr. Bancroft has been more definitely described, and its anatomy investigated, it may become evident that it is identical with the Filaria sanguinis hominis. Should such turn out to be the case, the etiological signification of the parasite will present a greater puzzle than ever, seeing that the affection of the scrotum of the character above reforred to-the affection described by Dr. Bristowe under the designation "elephantiasis lymphangiectodes" - would appear to be wholly unknown in Australia.

In conclusion, I desire to express the great obligation I am under to Dr. Gayer for the opportunities which he has afforded me of studying this subject in his wards.

calcutta.

\section{REMARKS ON}

\section{A CASE OF RARE DISLOCATION OF THE HIP.}

BY ARTHUR E. BARKER, F.R.C.S.I., ASSISTANT-SURGEON TO JNIVERSITY COLLEGE HOSPITAL.

Tre subjoined case, not only on account of its extreme rarity, but also of some other features of interest about it, may not be unworthy of publication where so much has lately been written on dislocations.

A boy aged nine years presented himself as one of my outpatients at University College Hospital on Thursday, April 5th, 1877. Coming into the room, he limped slightly, but apparently walked without any pain or much inconvenience. He was ruddy, healthy, and muscular, and had, his mother stated, been running about perfectly well until the preceding Friday. On this day, while at play, he made a spring to ride "pick-a-back" on one of his companions, but, missing his hold, fell. His mother described, almost unasked, the position in which his lower limbs were when he came down to the ground. The right was, according to her, strongly abducted and somewhat flexed, and the left doubled up under him as he fell on his nates. After the fall he felt some pain in the hip, and his mother noticed the following deformity, which was well marked when she brought him to me, and but for which she would not have come, so little distressed did he seem. The first point that caught the attention as the boy stood upright was that the right thigh was strongy abducted, and that in order to bring the foot to the ground he was obliged to tilt the pelvis down towards the right side; besides this, the thigh was slightly flexed on the trunk, and the foot slightly but distinctly everted. The next point that struck me, on removing his clothes, was a flattening of the thigh in the region of the great trochanter, and the obliteration of the fold of the nates also that the thigh was rigid-i.e., could not be flexed, adducted, or extended.

From the history of the violenee, the first thing that suggested itself to me was a dislocation into the thyroid foramen. But although, on laying the boy on his back and comparing the limbs when brought as nearly into the same plane as possible, I found there was an apparent lengthening of about an inch and a half, I saw that the pelvis was oblique to about the same extent. Then two careful independent measurements- the first by myself in one room, and the second by one of the house-surgeons, who was not then present, in another subsequently-showed real shortening of from a quarter to half an inch in the whole limb from the anterior superior spine of the ilium to the internal malleolus. The thigh could not be brought down on the bed without rotation of the whole pelvis. Aguin, searching for the position of the head of the bone, it was clearly not in the thyroid foramen or on the pubis. Then examining the buttock while the boy was under chloroform, I had a good opportunity of making out all the parts, and could come to no other conclusion than that the head lay just above the acetabulum, and that the trochanter was drawn backwards towards the sciatic foramen. It should be men tioned, again, that the long adductor of the thigh was very tense before chloroform was given, and that the thigh could neither be brought down from its condition of slight flexion nor inwards from its state of abduction without moving the whole pelvis, nor could it be flexed on the abdomen.

Reserving further comments for the present, I shall now describe the manner in which the dislocation was reduced. The boy being laid on his back on the operating table, I attempted without chloroform to adduct and flex the thigh on the abdomen, the pelvis being fixed by an assistant. This was impossible, owing to muscular resistance. Chloroform was then administered, and I was able, without the slightest exertion, to flex the thigh in the adducted position, and the leg on it; circumduction was then as easily effected, and at the same time rotation of the femur out wards on its own long axis, while the limb was being brought down at the end of the circumduction. It was plain, however, that the bone had not returned to its place. I then immediately made a fresh attempt in precisely the same manner, but without avail. I record these two efforts carefully, not because they were the proper movements to make, but because the fact of their failure tends to add clearness to the diagnosis when we consider the saovement that was successful. After a moment's pause I now drew the limb gently downwards in its long axis, and again adducted, flexed, and then circumducted the thigh as before, downward traction being kept up all the time on the head, but this time rotated the thigh inwards. This effort was perfectly successful, but as reduction was effected withou the slightest start or jerk of the bone as it returned to the socket, the fact was not apparent for a moment or two when I noticed that the limb was of its normal length, and now lay flat on the table like its fellow. The usual prominence of the trochanter was now well marked, as also the fold of the nates, and all the motions of the limb were perfectly restored. The obliquity of the pelvis had completely disappeared, and measurement showed the two limbs now equal in length. The trochanter had also come forward again, as indicated by its relation to the apex of the wellknown triangle drawn with pen and ink, before any attempt at reduction had been made. After reduction the tip of the trochanter was considerably anterior to the apex of the triangle to which it had previously corresponded.

In commenting on this case I should first like to state that the new position assumed by the dislocated head was not at all clear to the touch. But there could be no doubt at all that it was not on any part of the thyroid foramen or pubis proper, for there was no trace of fulness anywhere along the latter. It was also clear that the head was forwards and the trochanter backwards, for the latter could be easily felt near the tuber ischii, and the limb was everted.

Since writing these notes of this case on the day on which I reduced the dislocation, I have considered it in all its bearings with the help of all the books within my reach, and $I$ now believe that the conclusion arrived at then was, in the main, correct, and that the head of the femur was forced directly upwards, and lay just below, and a little outside of, the anterior inferior spinous process of the ilium, and immediately above, or upon, the brim of the acetabulum. I am aware that I spoke of this at the moment as an everted dorsal, which may be considered a misnomer, the term usually applied to this form being the "sub-spinous" (Bigelow) or "sus-cotyloidienne" (Malgaigne). It is, however, a variety of everted dorsal in one sense. (See Busch.)

Writing of this form of displacement ("subspinous") Bigelow says:- If thrust directly upwards the bone may lie beneath the $Y$ ligament and the inferior iliac spine; but this displacement requires that the upper part of the capsule should be completely detached from the edge of the socket. The firm bearing of the neck against the $V$ liga. ment may then explain how the patien has in some recordec cases [here he quotes Malgaigne] been able to walk imme. 